Gingival tissue human beta-defensin levels in relation to infection and inflammation.

\title{
Özdemir, Meltem
}

2020-03

Özdemir , M , Caglayan , F , Bigger , F , Pussinen , P, Könönen , E, Yamalik, N, Gursoy , M , Fteita , D , Nazmi , K, Güncü , G N , Pietiäinen , M , Tolvanen , M \& Gürsoy , U K 2020 , ' Gingival tissue human beta-defensin levels in relation to infection and inflammation. ', Journal of Clinical Periodontology , vol. 47 , no. 3 , pp. 309-318 . https://doi.org/10.1111/jcpe.13227

http://hdl.handle.net/10138/328536

https://doi.org/10.1111/jcpe.13227

acceptedVersion

Downloaded from Helda, University of Helsinki institutional repository.

This is an electronic reprint of the original article.

This reprint may differ from the original in pagination and typographic detail.

Please cite the original version. 
DR. GULIZ N. GUNCU (Orcid ID : 0000-0001-8456-5583)

DR. MILLA PIETIÄINEN (Orcid ID : 0000-0002-4875-0682)

DR. ULVI KAHRAMAN GURSOY (Orcid ID : 0000-0002-1225-5751)

Article type : Original Article Clinical Periodontology

\section{Gingival Tissue Human Beta-Defensin Levels in Relation to Infection and Inflammation}

\section{Running Title: Human Beta-Defensins in Periodontitis}

Meltem Özdemir ${ }^{1,2}$, Feriha Caglayan² ${ }^{2}$, Floris J. Bikker ${ }^{3}$, Pirkko Pussinen ${ }^{4}$, Eija Könönen ${ }^{1,5}$, Nermin Yamalik ${ }^{2}$, Mervi Gürsoy ${ }^{1}$, Dareen Fteita ${ }^{1}$, Kamran Nazmi ${ }^{3}$, Güliz N. Güncü ${ }^{2}$, Milla Pietiäinen ${ }^{4}$, Mimmi Tolvanen ${ }^{1}$, Ulvi Kahraman Gürsoy ${ }^{1}$

1 Department of Periodontology, Institute of Dentistry, University of Turku, Turku, Finland 2 Department of Periodontology, Faculty of Dentistry, Hacettepe University, Ankara, Turkey

3 Department of Oral Biochemistry, Academic Centre for Dentistry Amsterdam, Free University and University of Amsterdam, Amsterdam, The Netherlands

4 Department of Oral and Maxillofacial Diseases, University of Helsinki, Helsinki, Finland 5 Oral Health Care, Welfare Division, City of Turku, Turku, Finland

\section{Corresponding Author:}

Ulvi Kahraman Gürsoy

Institute of Dentistry, University of Turku, Lemminkäisenkatu 2, 20520, Turku, Finland Tel: +358 50514 8132; Email: ulvi.gursoy@utu.fi

This article has been accepted for publication and undergone full peer review but has not been through the copyediting, typesetting, pagination and proofreading process, which may lead to differences between this version and the Version of Record. Please cite this article as doi: $\underline{10.1111 / \text { JCPE. } 13227}$

This article is protected by copyright. All rights reserved 


\section{Acknowledgements}

This study is supported by TUBITAK, Turkey (M.Ö, Grant no: BIDEB- 1059B141700759), Finnish Dental Society Apollonia, Finland (UKG and PP), Turku University Foundation (D.F. Grant no: 12194), Hacettepe University Scientific Research Projects Coordination Units (MÖ, THD-16531), Sigrid Juselius foundation (PP), and Paulo foundation (PP).

The authors are grateful for the skillful technical assistances of Katja Sampalahti from University of Turku. Authors confirm that they have no conflict of interest.

\section{Abstract}

Aim: To profile gingival tissue levels of human beta-defensin (hBD)-2 and hBD-3 in relation to gingival inflammation, Th17-related cytokine concentrations, Porphyromonas gingivalis counts, and gingipain and total protease activities. 
Materials and Methods: Gingival tissue and subgingival plaque samples were collected from 21 periodontitis patients including 48 periodontal pocket sites with marginal, mild, or moderate to severe inflammation. hBD levels were determined by immunodetection, $P$. gingivalis counts with real-time polymerase chain reaction, protease activities with fluorogenic substrates, and cytokine concentrations with Luminex technique. Data were statistically analyzed using Kruskal-Wallis and Mann-Whitney U tests and Spearman correlation coefficients.

Results: Subgingival plaque counts of $P$. gingivalis $(\mathrm{p}=0.001)$ and gingipain activity $(\mathrm{p}<0.001)$, as well as interleukin (IL)-1 $\beta$ ( $p=0.012)$, IL-10 ( $\mathrm{p}=0.024)$, IL-17A ( $\mathrm{p}=0.002)$, IL-17F $(p=0.006)$, and IL-23 ( $p=0.036)$ concentrations were elevated in severely inflamed sites, whereas no change was observed in hBD-2 and hBD-3 levels. Negative correlations were found between protease activity and hBD-2 ( $\mathrm{p}=0.033)$ and hBD-3( $\mathrm{p}=0.003)$ levels.

Conclusions: Shift in gingival inflammation from marginal to mild stage is related to elevations in subgingival plaque $P$. gingivalis counts and gingipain activity, but not to tissue hBD levels. Negative correlations between hBDs and total protease activity suggest the degradation of these antimicrobial peptides in progressed inflammation.

Keywords: Periodontitis, antimicrobial peptides, hBD-2, hBD-3, Porphyromonas gingivalis, gingipain, inflammatory cytokines.

\section{Clinical Relevance:}

Scientific rationale for study: Human beta-defensins (hBDs) are small cationic peptides with antimicrobial and immune-regulatory roles and their expression and secretion are dependent on environmental (bacterial and inflammatory stimulation) and genetic factors.

Principal findings: Here, we demonstrated that the tissue hBD-2 and hBD-3 levels negatively correlate with enzymatic activity while Th17-related cytokine concentrations, Porphyromonas gingivalis counts, and gingipain activities relate to clinical gingival inflammation.

Practical implications: Understanding the activation and inactivation mechanisms of these antimicrobial and immune-regulatory peptides may enable to benefit from these biomolecules within the context of adjunctive periodontal therapy. 


\section{Introduction}

Human beta-defensins (hBDs) are small, cysteine-rich cationic peptides with bi-directional regulatory relations to the adaptive immune system, angiogenesis, and wound healing (SuarezCarmona et al., 2015). Gingival hBDs are produced by epithelial cells (Gomes and Fernandes, 2010) and are released into saliva (Gürsoy et al., 2016) and gingival crevicular fluid (Ertugrul et al., 2014, Yilmaz et al., 2018). While hBD-1 is secreted constitutively in periodontal tissues, hBD2 and hBD-3 secretions are activated by bacterial or inflammatory stimuli (Ganz, 2003).

Porphyromonas gingivalis is a Gram-negative, anaerobic, asaccharolytic, non-motile bacterium (Darveau et al., 2012). P. gingivalis gingipains are cysteine proteinases with a trypsin-like activity, including lysine-specific gingipain (Kgp) and arginine-specific gingipains (RgpA and RgpB); they account for $85 \%$ of the total proteolytic activity of $P$. gingivalis (Potempa et al. 1997). Gingipains selectively subverts the host's innate and adaptive immunity by inactivating anti-inflammatory cytokines and degrading antimicrobial peptides, including hBDs (Carlisle et al., 2009; Maisetta et al. 2011).

On one hand, cytokines, such as interleukin (IL)-1 $\beta$, IL-6, and IL-23, influence the differentiation of T helper 17 (Th17) cells. As a consequence, the increased release of Th17-related cytokines induces epithelial hBD expression (Kolls et al., 2008). On the other hand, infection either 
stimulates or suppresses the secretion of these antimicrobial peptides, depending on the virulence of the bacteria involved (Diamond and Ryan, 2011, Gursoy et al., 2012). Here, we hypothesized that clinical inflammation and Th17-related inflammatory cytokines activate; whereas $P$. gingivalis, its gingipain activity, and total protease activity suppress hBD levels in periodontally inflamed gingival tissue. In the present study, the aim was to profile the levels of hBD-2 and hBD-

3 in tissue samples with a specific reference for the severity and extent of clinical gingival inflammation and further, to correlate them with hBD-activating Th17-related cytokine concentrations, $P$. gingivalis counts, and hBD-degrading gingipain and total protease activities.

\section{Materials and Methods}

\section{Ethical Guidelines}

The study protocol (no: GO 17/786-34) was approved by the Ethical Committee of Hacettepe University, Ankara, Turkey in accordance with Helsinki Declaration 1975, as revised in year 2000. Oral and written information about the study protocol were given to potential participants. An informed consent was obtained from those willing to participate in the study.

\section{Study Population}

For the sample size calculation, GLIMMPSE 2.0.0 (General Linear Multivariate Model \& Sample Size), which is a tool for calculating power and sample size in multilevel and longitudinal studies with an $\alpha=0.05$ and $\beta=0.10$ targeting for $90 \%$ power with three response variables, was used. In the calculations, mean values and standard deviations for $P$. gingivalis $\alpha$-haemolytic, $\beta$-haemolytic and non-haemolytic counts were based on a study by Wong et al. (Wong et al., 2016). Since changes in variability can dramatically affect power and sample size results, a scale factor was used to evaluate the sample size in case of variability in the present study is bigger than that in the reference study. It was assumed that the correlation coefficient between periodontal pockets with and without infection would be 0.3 and the correlation coefficient between the different responses would be 0.7 . These analyses indicated that a required sample size would be a minimum of 16 participants with 48 sites. 
Twenty-one periodontitis patients (13 males and 8 females with age range of 24-70 years) referred to the Hacettepe University, Faculty of Dentistry, Department of Periodontology, were recruited for the study. These periodontitis patients were the first to apply for the study and fit to the inclusion criteria [met the criteria of the 2017 World Workshop for classification of periodontal and peri-implant diseases (Papapanou et al., 2018)]. Exclusion criteria included systemic diseases, smoking, pregnancy, lactation, use of antibiotics and/or anti-inflammatory drugs within 3 months preceding the study and periodontal treatment within 6 months before the baseline.

\section{Periodontal Examination}

A full periodontal examination was performed by a single calibrated examiner (M.Ö.). Probing pocket depth (PPD), modified gingival index (MGI) (Lobene, 1986), clinical attachment level (CAL), plaque index (PI) (Löe, 1967) and bleeding on probing (BOP) (Ainamo and Bay, 1975) were recorded at 4 sites (mesio-buccal, mid-buccal, disto-buccal, lingual/palatinal) per tooth by using a manual periodontal probe (UNC-15, Hu-Friedy, Chicago, IL, USA). Orthopantomographs were taken (Sirona Orthophos XG5, NY, USA) from all individuals to evaluate the presence and extent of alveolar bone loss at the sampling sites. The extent of alveolar bone loss (ABL) was graded into three categories: mild: $\mathrm{ABL}$ in cervical third of the root; moderate, $\mathrm{ABL}$ in the middle third of the root; and severe, ABL from the apical third of the root (Salminen et al., 2014). A total of 48 periodontal pocket sites ( 2 to 3 sites/patient) with PPD of 5-7 mm were included in the study. All pocket sites with PPD 5-7 mm were included unless the patient had more than one periodontal pocket with the same degree of inflammation and pocket depth. In such cases, only the tooth site that best reflects the degree of inflammation and being easily isolated (e.g. maxilla, anterior region) was enrolled for sample collection.

Based on the degree of inflammation as assessed by the MGI, the sampling sites were divided into three study groups:

Group 1: Marginal inflammation, slight changes in color and texture but not in all portions of gingival margin or papilla $(\mathrm{n}=13)$,

Group 2: Mild inflammation, slight changes in color and texture in all portions of gingival margin or papilla $(\mathrm{n}=16)$,

Group 3: Moderate to severe inflammation, bright surface, erythema, edema, ulceration or spontaneous bleeding tendency $(\mathrm{n}=19)$. 
Levels of clinical parameters (PPD, MGI, CAL, PI, ABL) for each group are given in Table 1.

\section{Clinical Sample Collection}

Subgingival plaque was collected by paper points as described elsewhere (Belibasakis et al., 2014). Briefly, after removing the supragingival plaque, 3 sterile absorbent paper points (size 40, VDW, Munich, Germany) were gently inserted apically into the same periodontal pocket, removed after $15 \mathrm{~s}$ and placed in an Eppendorf tube containing $500 \mu \mathrm{l}$ of phosphate-buffered saline (PBS).

Inflamed gingival granulation tissue was excised from the lateral pocket wall and junctional epithelium by using the sharp side of a Gracey curette (Hu-Friedy, Chicago, IL). Excision involved the entire pocket starting from the bottom of the periodontal pocket and ended at the marginal gingiva, preferably with a single stroke. Granulation tissue samples were placed in an Eppendorf tube containing $100 \mu \mathrm{l}$ of PBS. The tissue samples and the paper points were immediately placed and stored at $-80^{\circ} \mathrm{C}$ and transferred with dry ice to the Institute of Dentistry, University of Turku, Finland, for the laboratory analyses.

\section{Sample Preparations}

Each bacterial plaque sample was vortexed for $30 \mathrm{~s}$ and the suspension was aliquoted for analyses of gingipain and total protease activities and $P$. gingivalis concentrations.

Each granulation tissue sample was cut in small pieces, put into $500 \mu$ of lysis buffer $(50 \mathrm{mM}$ Tris-Cl, $150 \mathrm{mM} \mathrm{NaCl}$ and $1 \%$ Triton X-100), vortexed for $10 \mathrm{~s}$, and incubated at $4^{\circ} \mathrm{C}$ for $24 \mathrm{~h}$. After incubation, tissues were centrifuged at $10000 \mathrm{~g}$ for $1 \mathrm{~min}$ and supernatants were obtained. Activation of proteases during the extraction process was inhibited by performing the entire procedure at $4^{\circ} \mathrm{C}$. The supernatants were aliquoted for determinations of gingipain and total protease activities, and $P$. gingivalis, hBD-2, hBD-3, and inflammatory cytokine concentrations.

\section{Determination of $\boldsymbol{P}$. gingivalis Counts}

For the DNA extractions, $250 \mu \mathrm{l}$ of bacterial plaque samples and $100 \mu \mathrm{l}$ of gingival granulation tissue samples were transferred to the bead tubes (NucleoSpin ${ }^{\circledR}$ Microbial DNA kit, MacheryNagel) and mixed with $250 \mu \mathrm{MG}$ binding buffer and $25 \mu \mathrm{l}$ proteinase $\mathrm{K}$. Tubes were agitated in Mixer Mill MM301 (Retch) for $12 \mathrm{~min}$ at 30 Herz and centrifuged for $30 \mathrm{~s}$ at 
$11000 \mathrm{~g} .150 \mu \mathrm{l}$ of supernatant was transferred to a new tube and DNA was extracted with phenol-chloroform method and precipitated with $3 \mathrm{M} \mathrm{NaAc}$ (Green and Sambrook, 2017).Pelleted DNA was dissolved into $50 \mu \mathrm{l}$ of TE-buffer.

$P$. gingivalis counts in gingival granulation tissue (including both tissue resident and epithelial adherent bacterial cells) and bacterial plaque samples were analyzed using a quantitative single copy gene-based real-time polymerase chain reaction (qPCR) as previously described (Hyvärinen et al., 2009) with some modifications. Reaction mixtures (total volume $20 \mu \mathrm{l}$ ) contained $2 \mu \mathrm{l}$ of template DNA, $200 \mathrm{nM}$ primers (Thermo Fisher Scientific) and 1x Universal KAPA SYBR FAST qPCR mastermix (KAPA Biosystems, Merck) supplemented with 1x ROX Low reference dye. Tenfold dilution series of the pJet1.2/blunt-Pg plasmid containing the whole Pg waaA-gene, encoding 3-deoxy-Dmanno-oct-2-ulosonic acid (Kdo) transferase, were used to generate standard curve. qPCR analyses were performed with the QuantStudio 5 Real-Time PCR System (Thermo Fisher Scientific) with following steps: Initial denaturation at $95^{\circ} \mathrm{C}$ for $3 \mathrm{~min}$, followed by 40 cycles of $3 \mathrm{~s}$ at $95^{\circ} \mathrm{C}$ and $20 \mathrm{~s}$ at $60^{\circ} \mathrm{C}$. Dissociation curve was generated according to the default settings of the QuantStudio 5 real time PCR system. DNA extracted from saliva samples of $P$. gingivalis -positive subjects were used as a positive control and water as a negative control in each set of analysis. The data were analyzed with QuantStudio ${ }^{\mathrm{TM}}$ Design and Analysis Software and the results are presented as genomic copies/ng DNA. The detection limit for P. gingivalis was 23 genome equivalents, calculated from the standard curves used.

\section{Determination of Gingipain and Total Protease Activities}

To determine the $P$. gingivalis specific gingipain activity, fluorogenic substrates that contain Damino acids [FITC-Ahx-(L)Arg-(D)Arg-KDbc (RR)] and L-amino acids [(FITC-Ahx-(L)Arg(L) $A r g-K D b c)(r R)]$ were used (Kaman et al., 2012). The substrates were specifically developed for $P$. gingivalis and its gingipains, and their validation with positive controls has been previously published (Kaman et al., 2012; Galassi et al., 2012). A non-specific fluorogenic substrate, PEK054, was used to analyze the total protease activity in the samples (Janus et al., 2015).

Either $16 \mu \mathrm{M}$ of gingipain substrates or $8 \mu \mathrm{M}$ of PEK-054 were added in $50 \mu \mathrm{l}$ of plaque suspension, tissue supernatant or PBS as a negative control, all supplemented with $2.5 \mu \mathrm{M}$ of Lcysteine. The 96 -well plates were read at $37^{\circ} \mathrm{C}$ for $1 \mathrm{~h}$ with 2 -min intervals on a fluorescence microplate reader with Gen5 software (Ex:485 nm - Em: 530 nm, Biotek Instruments, Winooski, VT, US). The protease activity was defined in relative fluorescence activity per $\mathrm{min}(\mathrm{RF} / \mathrm{min})$ as 
previously described (Kaman et al., 2012, Janus et al., 2015). All enzyme tests were performed in triplicate and repeated 3 times.

\section{Determination of hBD-2 and hBD-3 by Immunodetection}

Protein concentrations of each sample were determined by the Bradford method (Bio-Rad Laboratories Inc., Hercules, CA, USA). A same amount of protein $(10 \mu \mathrm{g} / \mathrm{mL}, 144 \mathrm{ng})$ for each sample was mixed with $5 \mu 1$ of Laemmli sample buffer $(4 \mathrm{x})$, and the mixture was heated at $95^{\circ} \mathrm{C}$ for $5 \mathrm{~min}$. Synthetic hBD-2 (0.034 mM, 4338-s, Peptide Institute, Inc., Osaka, Japan) and hBD-3 (0.034 mM, 4382-s Peptide Institute Inc.) were used as controls. The samples and purified proteins were loaded on $15 \%$ sodium dodecyl sulfate (SDS)-polyacrylamide gels at non-reducing conditions. After electrophoresis, the proteins were transferred to $0.2 \mu \mathrm{m}$ PVDF membranes (Trans-Blot ${ }^{\circledR}$ Turbo ${ }^{\text {TM }}$ Transfer System, Bio-Rad Laboratories Inc.). Membranes were blocked with $5 \%$ non-fat dry milk at room temperature for $1 \mathrm{~h}$ and incubated overnight with primary antibodies against hBD-2 (1:1000 dilution, \#AF2758, R\&D Systems, Minneapolis, MN) and hBD3 (1:750 dilution, \# PA1-4216Thermo Fisher Scientific, Inc., Waltham, MA) at $4^{\circ} \mathrm{C}$. To detect hBD-2, the membranes were incubated with HRP conjugated polyclonal rabbit anti-goat IgG $(\mathrm{H}+\mathrm{L})$ secondary antibody (1:2000 dilution \#81-1620, 4216Thermo Fisher Scientific, Inc., Waltham, MA). To detect hBD-3, the membranes were incubated with HRP conjugated polyclonal goat anti-rabbit IgG secondary antibody (1:2000 dilution, LS-C60884, LSBio, Seattle, WA).

Loaded protein levels were controlled with Coomassie blue staining (Welinder and Ekblad, 2011) and protein transfer was controlled with Ponceau S red stain. The proteins were visualized using Clarity ${ }^{\mathrm{TM}}$ Western ECL Substrate $(0.6 \mathrm{ml} / \mathrm{cm} 2$ area, \#170-5060, Bio-Rad Laboratories, Hercules, CA) and ChemiDoc ${ }^{\mathrm{TM}}$ MP Imaging System (Bio-Rad Laboratories). The bands were analyzed with the ImageJ software (National Institute of Health, Bethesda, Maryland, USA). All experiments were performed in triplicate at 2 different time points. Results of the Western-Blot analysis were additionally verified by using different primary antibodies than described above (for hBD-2 LSBio LS-B13646, Seattle, WA used with 1:1000 and 1:500 dilutions and for hBD-3 LSBio LS-C40649, Seattle, WA used with 1:500 dilution). Control experiments were performed by omitting the primary antibody from the immunodetections.

\section{Cytokine Concentrations}

Tissue concentrations of IL-1 $\beta$, IL-4, IL-6, IL-10, IL-17A, IL-17F, IL-21, IL-22, IL-23, IL-25, IL31, IL-33, interferon gamma (IFN- $\gamma$ ), soluble CD40 ligand (sCD-40L), and tumor necrosis factor- 
a (TNF- $\alpha$ ) were detected by the Luminex technique (Bio-Rad, Santa Rosa, CA, USA) with the commercial kits (Bio-Plex, pro-human Th17 cytokine assays; Bio-Rad) according to the manufacturer's instructions. Tissue extracts were vortexed, centrifuged at $9300 \mathrm{~g}$ for $10 \mathrm{~s}$, and a same amount of protein was taken from each tissue extract to determine the cytokine concentrations. The limit of detection of the assay was $0.02 \mathrm{pg} / \mathrm{ml}$ for IL- $1 \beta, 0.52 \mathrm{pg} / \mathrm{ml}$ for IL-4, $0.67 \mathrm{pg} / \mathrm{ml}$ for IL-6, $0.30 \mathrm{pg} / \mathrm{ml}$ for IL-10, $0.49 \mathrm{pg} / \mathrm{ml}$ for IL-17A, $0.80 \mathrm{pg} / \mathrm{ml}$ for IL-17F, 2.13 $\mathrm{pg} / \mathrm{ml}$ for IL-21, $0.30 \mathrm{pg} / \mathrm{ml}$ for IL-22, $1.55 \mathrm{pg} / \mathrm{ml}$ for IL-23, $0.07 \mathrm{pg} / \mathrm{ml}$ for IL-25, $0.49 \mathrm{pg} / \mathrm{ml}$ for IL-31, $0.58 \mathrm{pg} / \mathrm{ml}$ for IL-33, $0.43 \mathrm{pg} / \mathrm{ml}$ for IFN- $\gamma, 0.41 \mathrm{pg} / \mathrm{ml}$ for sCD-40L, and $0.07 \mathrm{pg} / \mathrm{ml}$ for TNF- $\alpha$.

\section{Statistical Analyses}

Data distributions were analyzed with Q-Q plots and the Shapiro-Wilk test. The IBM SPSS V24.0 software (IBM, Armonk, North Castle, New York, USA) was used for statistical analyses, including the non-parametric Kruskal-Wallis (for multiple comparisons) and MannWhitney $U$ tests and $p<0.05$ was accepted as statistically significant. Associations between variables were evaluated with Spearman correlation coefficients.

\section{Results}

There were no significant differences in CAL, PPD, and ABL levels among the study groups. PI levels were significantly higher at Group 3 than Group $1(\mathrm{p}<0.001)$ and Group $2(\mathrm{p}=0.001)$. BOP percentage was significantly lower at Group 1 than Group 2 ( $p=0.007)$ and Group $3(p=0.004)$. Molecular forms and relative levels of hBD-2 and hBD-3 in gingival tissue samples are given in Figure 1. Both hBDs were detected as dimers appearing at $\sim 12 \mathrm{kDa}$. Additional 3 bands appeared at 25,37 , and $150 \mathrm{kDa}$ and were defined as light and heavy chains of $\mathrm{IgG}$, as previously described (Herrera et al., 2016). There were no significant differences at hBD-2 and hBD-3 levels between the groups (Figure 1).

In subgingival plaque samples, $P$. gingivalis counts and its gingipain activities, as determined with the fluorogenic protease substrate RR were significantly higher at sites with mild inflammation (group 2) and with moderate to severe inflammation (group 3) than at sites presenting solely with marginal inflammation (group 1) (Table 2). No difference was observed between the groups as regards to $P$. gingivalis counts and its gingipain enzyme activities in gingival tissue samples (Table 3). 
All cytokine concentrations were above the lowest limit of detection (LLOD) except for IL-4 (29\% under LLOD), IL-10 (22.9\% under LLOD), IL-17F (16.6\% under LLOD), and IL-23 (16.6\% under LLOD). In descriptive analyses, cytokine concentrations below the minimum detection limit were substituted with a value of LLOD divided by 2 (Lubin et al., 2004). In gingival tissues with moderate to severe inflammation (group 3), IL-1ß, IL-10, IL-17A, IL-17F, and IL-23 concentrations were higher than in tissues with mild inflammation (group 2) (Table 4).

There were negative correlations between gingival tissue protease activity and hBD-2 $(\mathrm{p}=0.033)$ and hBD-3 ( $p=0.003$ ) (Table 5). IL-1 $\beta(p=0.007)$, IL-4 ( $p=0.012)$, IL-17F ( $p=0.035)$, IL-23 $(p=0.031), I L-25(p=0.01)$, and IL-31 $(p=0.039)$ showed positive and IL-33 $(p=0.035)$ showed negative correlation with gingival tissue gingipain (RR) activity.

\section{Discussion}

The results revealed that hBD-2 and hBD-3 form dimers in gingival tissues and their levels negatively correlate with total protease activity. To the best of our knowledge, this study is the first to analyze hBD-2 and hBD-3 levels in gingival granulation tissue in relation to the hBDsuppressing pathogenic activity (including $P$. gingivalis count, and gingipain and total protease activities) and hBD-inducing inflammatory response (Th17-related inflammatory cytokines). In the present study, the tissue samples were collected from periodontitis patients with various levels of clinical gingival inflammation, and granulation tissue of periodontal pocket was selected since it can be considered as the most active and appropriate site reflecting an ongoing disease. There was no ethical justification and clinical indication to excise sulcular tissue of healthy gingiva (no inflammation) from residual periodontal pockets with PPD 5-7 mm, thus no periodontally healthy control group was included in the protocol, which, however, may be regarded as a limitation of the study. Another limitation may be the fact that smokers were not included in the present study. The effect of smoking on tissue destruction in periodontal disease is well-described (Johnson and Guthmiller, 2007). Indeed, smoking may alter the innate immune response by suppressing hBD-2 in gingival epithelial cells as well (Mahanonda et al., 2009). A continuation study with smokers and quitters will enlighten the impact of smoking on the interactions between periodontal pathogens, inflammatory response, and gingival antimicrobial peptides. Finally, protease inhibitors were not used during sample storage and analysis in order not to interrupt the enzyme activity measurements. This may, at least partly, affect the levels of hBDs, 
as they are prone to enzymatic degradation, since sample storage and preparation at $4{ }^{\circ} \mathrm{C}$ may not inhibit proteolysis totally.

hBDs are small cationic peptides of 4-5kDa. We found gingival hBD-2 and hBD-3 in dimer forms at around $12 \mathrm{kDa}$ levels. Recently, dimeric forms of hBD-2 and hBD-3 at $\sim 12 \mathrm{kDa}$ were shown in human tonsil cells (Herrera et al., 2016). The authors demonstrated that additional three bands at 25, 37 and $150 \mathrm{kDa}$ proved to be the light and heavy chains of IgG. These additional bands were also detected in gingival tissue (Figure 1). Our findings were validated by running the immunoblottings 1) at reduced conditions, 2) in the absence of primary antibodies, and 3) with different primary and secondary antibodies. In hBDs, dimerization is a precursor for higher oligomerization (Hoover et al., 2000). It was postulated that the presence of hBD-2 in the higher oligomeric forms facilitates its function by increasing cationicity and by enhancing the bacterial membrane permeability when compared with monomeric forms. In solutions, dominant oligomeric forms of hBD-2 have been found to be dimers (Hoover et al., 2000). Yet, it is unclear whether the dimerization observed in the present study is formed in the gingiva or after tissue extraction. Synthetic hBD-2 and hBD-3, which we used as positive controls, were also found in the same kDa region. As suggested by Suresh and Verma (2006), the observed peptide forms can be outcomes of the test conditions and/or high peptide concentrations. Thus, for confirming our findings, different extraction and analyzing techniques, (e.g., mass-spectrometry) will be needed. According to our results, tissue levels of hBDs do not relate to the severity of gingival inflammation. Previous studies demonstrated controversial findings in terms of the relation between periodontal inflammation and hBD levels; RNA and protein expression profiles of hBDs in periodontitis and in experimental gingivitis models were found to be elevated, steady or suppressed (Offenbacher et al., 2009; Pereira et al., 2012; Yilmaz et al., 2015; Dommisch et al., 2015, 2019; Jourdain et al., 2019). Although our results are in line with the report of Li et al., (2016), in which no difference was observed in hBD-2 and hBD-3 gene expression levels between healthy and inflamed gingiva, longitudinal study designs are required to understand the shifts in inflammation-related regulation of hBD expression.

In the present study, elevated tissue levels of IL-1 $\beta$, IL-10, IL-17A, IL-17F, and IL-23 were in line with the increase in inflammatory status of gingival samples. Previously, IL-1 $\beta$ and IL-17 have been shown to lead to an increased hBD-2 release from keratinocytes, while IL-10 decreased hBD-2 expression (Kanda et al., 2011). In our study, however, no relation was found between hBD levels and the amount of these inflammatory cytokines. On one hand, elevated inflammatory 
cell (neutrophils, macrophages) infiltration to the sulcular granulation tissue may lead to a significant increase in cytokine levels. On the other hand, the disturbed epithelial structure and integrity in the granulation tissue may negatively affect the release of antimicrobial defensins from keratinocytes. Thus, characteristics of the sample tissue seem to have a major contribution to the levels of inflammatory cytokines and antimicrobial peptides.

Based on our results, a shift from marginal to mild inflammation is related to the elevated levels of $P$. gingivalis and related gingipain activity in plaque samples. On the other hand, no significant difference was found in $P$. gingivalis counts and gingipain activity between mild and severe inflammation groups. There are controversial results in regard to correlation between the levels of $P$. gingivalis and severity of gingival inflammation; both positive correlation (Demmer et al., 2008) and no correlation (Suda et al., 2004) have been presented. Indeed, it was also proposed that, as an opportunist bacterium, $P$. gingivalis can subvert host defense mechanisms to prolong its survival and establishment in the periodontal pocket, but at the same time does not aggravate the inflammatory response in order to disable adaptive immunity (Hajishengallis, 2011). It is possible to claim that the correlation between the degree of gingival inflammation and $P$. gingivalis counts and activity does not necessarily be linear, but may have exponential and stationary phases. However, the cross-sectional design of the present study does not allow us to differentiate these active interactions between the host response and bacterium.

To asses gingipain activity, two different fluorogenic substrates (RR and rR), with different amino acid configurations, were used. These two fluorogenic substrates have been developed to detect the presence of $P$. gingivalis by measuring gingipain activity with a high sensitivity and specificity (RR has a sensitivity of $70 \%$ and specificity of $96 \%$, rR has a sensitivity of $95 \%$ and specificity of 73\%) (Kaman et al., 2012). In our study, the tissue and plaque RR activities and plaque rR activity showed a positive correlation with the amount of $P$. gingivalis in the same sample. In addition, hBD-2 and hBD-3 levels had a negative correlation with total protease activity in gingival tissue, while no correlation was observed with gingipain activity. hBDs are known to be susceptible to degradation by bacterial proteases (Maisetta et al., 2011) and host proteases, such as by cathepsins (Taggart et al., 2003). Negative correlations between the total enzyme activity and hBD levels may indicate that the elevated bacteria- and host-induced protease activities in inflamed tissues may degrade or inactivate gingival tissue hBDs, leading to a shift from an insufficient innate immune response to a more aggressive humoral immune response. 
To conclude, subgingival plaque levels of $P$. gingivalis and gingipain activity and tissue levels of

Th17-related inflammatory cytokines, but not hBD levels in gingival tissue, are related to the severity of clinical periodontal inflammation. Negative correlations between the hBDs and gingival tissue total protease activity may indicate the degradation of these antimicrobial peptides in progressed inflammation, which was previously demonstrated only in in vitro studies.

\section{References}

Ainamo, J. \& Bay, I. (1975) Problems and proposals for recording gingivitis and plaque. International Dental Journal 25, 229-235.

Belibasakis, G. N., Schmidlin, P. R. \& Sahrmann, P. (2014) Molecular microbiological evaluation of subgingival biofilm sampling by paper point and curette. Apmis 122, 347-352.

Carlisle, M. D., Srikantha, R. N. \& Brogden, K. A. (2009) Degradation of human alpha- and betadefensins by culture supernatants of Porphyromonas gingivalis strain 381 . J Innate Immunity 1, 118-122.

Darveau, R., Hajishengallis, G. \& Curtis, M. (2012) Porphyromonas gingivalis as a potential community activist for disease. Journal of Dental Research 91, 816-820.

Demmer, R. T., Papapanou, P. N., Jacobs Jr, D. R. \& Desvarieux, M. (2008) Bleeding on probing differentially relates to bacterial profiles: the oral infections and vascular disease epidemiology study. Journal of Clinical Periodontology 35, 479-486.

Diamond, G. \& Ryan, L. (2011) Beta-defensins: what are they really doing in the oral cavity? Oral Diseases 17, 628-635.

Dommisch, H., Staufenbiel, I., Schulze, K., Stiesch, M., Winkel, A., Fimmers, R., Dommisch, J., Jepsen, S., Miosge, N. \& Adam, K. (2015) Expression of antimicrobial peptides and interleukin-8 during early stages of inflammation: an experimental gingivitis study. Journal of Periodontal Research 50, 836-845.

Dommisch, H., Skora, P., Hirschfeld, J., Olk, G., Hildebrandt, L. \& Jepsen, S. (2019) The guardians of the periodontium-sequential and differential expression of antimicrobial peptides during gingival inflammation. Results from in vivo and in vitro studies. Journal of Clinical Periodontology 46, 276-285. 
Ertugrul, A., Sahin, H., Dikilitas, A., Alpaslan, N., Bozoğlan, A. \& Tekin, Y. (2014) Gingival crevicular fluid levels of human beta-defensin-2 and cathelicidin in smoker and nonsmoker patients: a cross-sectional study. Journal of Periodontal Research 49, 282-289.

Galassi, F., Kaman, W.E., Anssari Moin, D., van der Horst, J., Wismeijer, D., Crielaard, W., Laine, M.L., Veerman, E.C., Bikker, F.J. \& Loos, B.G. (2012) Comparing culture, realtime PCR and fluorescence resonance energy transfer technology for detection of Porphyromonas gingivalis in patients with or without peri-implant infections. Journal of Periodontal Research 47, 616-625.

Ganz, T. (2003) Defensins: antimicrobial peptides of innate immunity. Nature Reviews Immunology 3, 710.

Gomes, P. d. S. \& Fernandes, M. H. (2010) Defensins in the oral cavity: distribution and biological role. Journal of Oral Pathology \& Medicine 39, 1-9.

Green, M. R. \& Sambrook, J. (2017) Isolation of high-molecular-weight DNA using organic solvents. Cold Spring Harbor Protocols 2017, pdb. prot093450.

Gursoy, U. K., Pöllänen, M., Könönen, E. \& Uitto, V. J. (2012) A novel organotypic dentoepithelial culture model: effect of Fusobacterium nucleatum biofilm on B-defensin-2,-3, and LL-37 expression. Journal of Periodontology 83, 242-247.

Gürsoy, M., Gürsoy, U. K., Liukkonen, A., Kauko, T., Penkkala, S. \& Könönen, E. (2016) Salivary antimicrobial defensins in pregnancy. Journal of Clinical Periodontology 43, 807815.

Hajishengallis, G. (2011) Immune evasion strategies of Porphyromonas gingivalis. Journal of Oral Biosciences 53, 233-240.

Herrera, R., Morris, M., Rosbe, K., Feng, Z., Weinberg, A. \& Tugizov, S. (2016) Human betadefensins 2 and-3 cointernalize with human immunodeficiency virus via heparan sulfate proteoglycans and reduce infectivity of intracellular virions in tonsil epithelial cells. Virology 487, 172-187.

Hoover, D. M., Rajashankar, K. R., Blumenthal, R., Puri, A., Oppenheim, J. J., Chertov, O. \& Lubkowski, J. (2000) The structure of human $\beta$-defensin-2 shows evidence of higher order oligomerization. Journal of Biological Chemistry 275, 32911-32918.

Hyvärinen, K., Laitinen, S., Paju, S., Hakala, A., Suominen-Taipale, L., Skurnik, M., Könönen, E. \& Pussinen, P. J. (2009) Detection and quantification of five major periodontal pathogens by single copy gene-based real-time PCR. Innate Immunity 15, 195-204. 
Janus, M. M., Keijser, B. J., Bikker, F. J., Exterkate, R. A., Crielaard, W. \& Krom, B. P. (2015) In vitro phenotypic differentiation towards commensal and pathogenic oral biofilms. Biofouling 31, 503-510.

Johnson, G. K. \& Guthmiller, J. M. (2007) The impact of cigarette smoking on periodontal disease and treatment. Periodontology 2000 44, 178-194.

Jourdain, M. L., Velard, F., Pierrard, L., Sergheraert, J., Gangloff, S. C. \& Braux, J. (2019) Cationic antimicrobial peptides and periodontal physiopathology: A systematic review. Journal of Periodontal Research 54, 589-600.

Kaman, W. E., Galassi, F., de Soet, J. J., Bizzarro, S., Loos, B. G., Veerman, E. C., van Belkum, A., Hays, J. P. \& Bikker, F. J. (2012) Highly specific protease-based approach for detection of Porphyromonas gingivalis in diagnosis of periodontitis. Journal of Clinical Microbiology 50, 104-112.

Kanda, N., Kamata, M., Tada, Y., Ishikawa, T., Sato, S. \& Watanabe, S. (2011) Human $\beta$ defensin- 2 enhances IFN- $\gamma$ and IL-10 production and suppresses IL-17 production in T cells. Journal of Leukocyte Biology 89, 935-944.

Kolls, J. K., McCray Jr, P. B. \& Chan, Y. R. (2008) Cytokine-mediated regulation of antimicrobial proteins. Nature Reviews Immunology 8, 829.

Lobene, R. (1986) A modified gingival index for use in clinical trials. Clin. Prevent. Dent. 8, 3-6.

Li, X., Duan, D., Yang, J., Wang, P., Han, B., Zhao, L., Jepsen, S., Dommisch, H, Winter, J. \& $\mathrm{Xu}, \mathrm{Y}$. (2016) The expression of human $\beta$-defensins (hBD-1, hBD-2, hBD-3, hBD-4) in gingival epithelia. Archives of Oral Biology 66, 15-21.

Löe, H. (1967) The gingival index, the plaque index and the retention index systems. The Journal of Periodontology 38, 610-616.

Lubin, J. H., Colt, J. S., Camann, D., Davis, S., Cerhan, J. R., Severson, R. K., Bernstein, L. \& Hartge, P. (2004) Epidemiologic evaluation of measurement data in the presence of detection limits. Environmental Health Perspectives 112, 1691.

Mahanonda, R., Sa-Ard-Iam, N., Eksomtramate, M., Rerkyen, P., Phairat, B., Schaecher, K., Fukuda, M. \& Pichyangkul, S. (2009) Cigarette smoke extract modulates human $\beta$ defensin-2 and interleukin-8 expression in human gingival epithelial cells. Journal of Periodontal Research 44, 557-564. 
Maisetta, G., Brancatisano, F. L., Esin, S., Campa, M. \& Batoni, G. (2011) Gingipains produced by Porphyromonas gingivalis ATCC49417 degrade human- $\beta$-defensin 3 and affect peptide's antibacterial activity in vitro. Peptides 32, 1073-1077.

Offenbacher, S., Barros, S. P., Paquette, D. W., Winston, J. L., Biesbrock, A. R., Thomason, R. G., Gibb, R. D., Fulmer, A. W., Tiesman, J. P. \& Juhlin, K. D. (2009) Gingival transcriptome patterns during induction and resolution of experimental gingivitis in humans. Journal of Periodontology 80, 1963-1982.

Papapanou, P. N., Sanz, M., Buduneli, N., Dietrich, T., Feres, M., Fine, D. H., Flemmig, T. F., Garcia, R., Giannobile, W. V., Graziani, F., Greenwell, H., Herrera, D., Kao, R. T., Kebschull, M., Kinane, D. F., Kirkwood, K. L., Kocher, T., Kornman, K. S., Kumar, P. S., Loos, B. G., Machtei, E., Meng, H., Mombelli, A., Needleman, I., Offenbacher, S., Seymour, G. J., Teles, R. \& Tonetti, M. S. (2018) Periodontitis: Consensus report of workgroup 2 of the 2017 World Workshop on the Classification of Periodontal and PeriImplant Diseases and Conditions. Journal of Clinical Periodontology 45 Suppl 20, S162S170.

Pereira, A. L., Holzhausen, M., Franco, G. C. N., Cortelli, S. C. \& Cortelli, J. R. (2012) Human $\beta$ defensin 2 and protease activated receptor-2 expression in patients with chronic periodontitis. Archives of Oral Biology 57, 1609-1614.

Potempa, J., Pike, R. \& Travis, J. (1997) Titration and mapping of the active site of cysteine proteinases from Porphyromonas gingivalis (gingipains) using peptidyl chloromethanes. Biological Chemistry 378, 223-230.

Salminen, A., Gursoy, U. K., Paju, S., Hyvärinen, K., Mäntylä, P., Buhlin, K., Könönen, E., Nieminen, M. S., Sorsa, T., Sinisalo, J. \& Pussinen, P. J. (2014) Salivary biomarkers of bacterial burden, inflammatory response, and tissue destruction in periodontitis. Journal of Clinical Periodontology 41, 442-50.

Suarez-Carmona, M., Hubert, P., Delvenne, P. \& Herfs, M. (2015) Defensins:"simple" antimicrobial peptides or broad-spectrum molecules? Cytokine \& Growth Factor Reviews 26, 361-370.

Suda, R., Kobayashi, M., Nanba, R., Iwamaru, M., Hayashi, Y., Lai, C. H. \& Hasegawa, K. (2004) Possible periodontal pathogens associated with clinical symptoms of periodontal disease in japanese high school students. Journal of Periodontology 75, 1084-1089. 
Suresh, A. \& Verma, C. (2006) Modelling study of dimerization in mammalian defensins. $B M C$ Bioinformatics 18, S17.

Taggart, C. C., Greene, C. M., Smith, S. G., Levine, R. L., McCray, P. B., O’Neill, S. \& McElvaney, N. G. (2003) Inactivation of human $\beta$-defensins 2 and 3 by elastolytic cathepsins. The Journal of Immunology 171, 931-937.

Welinder, C. \& Ekblad, L. (2011) Coomassie staining as loading control in Western blot analysis. Journal of Proteome Research 10, 1416-1419.

Wong, B. K., McGregor, N. R., Butt, H. L., Knight, R., Liu, L. Y. \& Darby, I. B. (2016) Association of clinical parameters with periodontal bacterial haemolytic activity. Journal of Clinical Periodontology 43, 503-511.

Y1lmaz, D., Güncü, G.N., Könönen, E., Barış, E., Çağlayan, F. \& Gursoy, U. K. (2015) Overexpressions of hBD-2, hBD-3, and hCAP18/LL-37 in gingiva of diabetics with periodontitis. Immunobiology 220, 1219-1226.

Yilmaz, D., Caglayan, F., Buber, E., Könönen, E., Aksoy, Y., Gursoy, U. K. \& Guncu, G. N. (2018) Gingival crevicular fluid levels of human beta-defensin-1 in type 2 diabetes mellitus and periodontitis. Clinical Oral Investigations 22, 2135-2140. 
Table 1: Probing pocket depth (PPD), modified gingival index (MGI), clinical attachment level (CAL), plaque index (PI), bleeding on probing (BOP), and alveolar bone loss levels of each study group (Group 1: marginal inflammation, Group 2: mild inflammation, Group 3: moderate to severe inflammation).

\begin{tabular}{|c|c|c|c|}
\hline & $\begin{array}{l}\text { Group } 1 \\
n=13\end{array}$ & $\begin{array}{l}\text { Group } 2 \\
n=16\end{array}$ & $\begin{array}{l}\text { Group } 3 \\
n=19\end{array}$ \\
\hline PPD (mean \pm st. dev.) & $5.15 \pm 0.56$ & $5.38 \pm 0.81$ & $5.16 \pm 0.38$ \\
\hline \% of sites with PPD $5 \mathrm{~mm}$ & 92.3 & 81.2 & 84.2 \\
\hline \% of sites with PPD $6 \mathrm{~mm}$ & 0 & 0 & 15.8 \\
\hline$\%$ of sites with PPD $7 \mathrm{~mm}$ & 7.7 & 18.8 & 0 \\
\hline MGI (mean \pm st. dev.) & $1 \pm 0$ & $2 \pm 0$ & $3.26 \pm 0.45$ \\
\hline CAL (mean \pm st. dev.) & $6.23 \pm 1.17$ & $6.31 \pm 1.25$ & $6.37 \pm 0.9$ \\
\hline$\%$ of sites with CAL $>7 \mathrm{~mm}$ & 84.6 & 81.25 & 84.2 \\
\hline$\%$ of sites with CAL 5-7 mm & 15.4 & 18.75 & 15.8 \\
\hline PI (mean \pm st. dev.) & $1.38 \pm 0.51$ & $1.75 \pm 0.45$ & $2.37 \pm 0.5$ \\
\hline$\%$ of sites with BOP & 61.5 & 100 & 100 \\
\hline$\%$ of sites with mild ABL & 76.9 & 43.8 & 42.1 \\
\hline$\%$ of sites with moderate $A B L$ & 15.4 & 50 & 42.1 \\
\hline$\%$ of sites with severe $A B L$ & 7.7 & 6.2 & 15.8 \\
\hline
\end{tabular}


Table 2: Subgingival plaque counts of $P$. gingivalis and its gingipain activities in the study groups (Group 1: marginal inflammation, Group 2: mild inflammation, Group 3: moderate to severe inflammation). Enzyme activities are presented in relative fluorescence per minute (RF/min). $p$ values in bold indicate a significant difference $(p<0.05)$ after multiple comparisons.

\section{Group $1(n=13) \quad$ Group $2(n=16) \quad$ Group $3(n=19) \quad p$ value $\quad p$ value $\quad p$ value} median (min-max) $\quad$ median (min-max) $\quad$ median (min-max) $\quad$ (Group 1 vs 2) $\quad$ (Group 1 vs 3) $\quad$ (Group 2 vs 3)

\begin{tabular}{|c|c|c|c|c|c|c|}
\hline $\begin{array}{c}P . \text { gingivalis } \\
\text { (count) }\end{array}$ & $1643(1-108012)$ & $29529(1-72257)$ & $17468(0-118284)$ & 0.012 & 0.001 & 0.78 \\
\hline $\mathbf{R} \mathbf{R}(\mathrm{RF} / \mathrm{min})$ & $0.85(0.25-6.5)$ & $5.1(0.55-17.75)$ & $5.65(0.65-33.85)$ & 0.001 & $<0.001$ & 0.52 \\
\hline $\mathbf{r R}(\mathrm{RF} / \mathrm{min})$ & $0.35(0-2.2)$ & $0.78(0-5.65)$ & $0.55(0-8.7)$ & 0.056 & 0.14 & 0.66 \\
\hline PEK-054 (RF/min) & $0(0-35.75)$ & $0.06(0-53.88)$ & $0.13(0-180)$ & 1 & 0.85 & 0.78 \\
\hline
\end{tabular}

RR: Gingipain specific substrate that contains D-aminoacids; rR: Gingipain specific substrate that contains L-aminoacids; PEK-054: Substrate to determine total protease enzyme activity 
Table 3: Gingival tissue counts of $P$. gingivalis and its gingipain activities in the study groups (Group 1: marginal inflammation, Group 2: mild inflammation, Group 3: moderate to severe inflammation). Enzyme activities are presented in relative fluorescence per minute (RF/min). $p$ values in bold indicate a significant difference $(p<0.05)$ after multiple comparisons.

$\begin{array}{cccccc}\text { Group } 1(\mathrm{n}=13) & \text { Group } 2(\mathrm{n}=16) & \text { Group } 3(\mathrm{n}=19) & p \text { value } & p \text { value } & p \text { value } \\ \text { median (min-max) } & \text { median (min-max) } & \text { median (min-max) } & \text { (Group 1 vs 2) } & \text { (Group 1 vs 3) } & \text { (Group 2 vs } 3 \text { ) }\end{array}$

\begin{tabular}{|c|c|c|c|c|c|c|}
\hline $\begin{array}{c}\text { P. gingivalis } \\
\text { (count/ng DNA) }\end{array}$ & $6(0-439)$ & $11.5(0-59)$ & $4(0-150)$ & 0.81 & 0.71 & 0.35 \\
\hline $\mathbf{R R}(\mathrm{RF} / \mathrm{min})$ & $0.83(0-9.67)$ & $1(0.5-37.2)$ & $2.5(0.17-65.5)$ & 0.42 & 0.08 & 0.08 \\
\hline PEK-054 (RF/min) & $84.5(35.2-128)$ & $94.3(38-130)$ & $109(16.2-172)$ & 0.45 & 0.22 & 0.52 \\
\hline
\end{tabular}

RR: Gingipain specific substrate that contains D-aminoacids; rR: Gingipain specific substrate that contains L-aminoacids; PEK-054: Substrate to determine total protease enzyme activity 
Table 4: Tissue concentrations of examined cytokines ( $\mathrm{pg} / \mathrm{ml})$ in the study groups (Group 1: marginal inflammation, Group 2: mild inflammation, Group 3: moderate to severe inflammation). $p$ values in bold indicate a significant difference $(p<0.05)$ after multiple comparisons.

\begin{tabular}{|c|c|c|c|c|c|c|}
\hline & $\begin{array}{c}\text { Group 1 } \\
(\mathrm{n}=13) \\
\text { median (min-max) }\end{array}$ & $\begin{array}{c}\text { Group 2 } \\
(\mathrm{n}=16) \\
\text { median (min-max) }\end{array}$ & $\begin{array}{c}\text { Group 3 } \\
(\mathrm{n}=19) \\
\text { median (min-max) }\end{array}$ & $\begin{array}{c}p \text { value } \\
\text { (Group } 1 \text { vs 2) }\end{array}$ & $\begin{array}{c}p \text { value } \\
\text { (Group } 1 \text { vs 3) }\end{array}$ & $\begin{array}{c}p \text { value } \\
\text { (Group } 2 \text { vs 3) }\end{array}$ \\
\hline IL-1 $\beta$ & $33.46(8.21-218)$ & $37.31(8.64-177)$ & $95.78(6.71-287)$ & 0.861 & 0.088 & 0.012 \\
\hline IL-4 & $1.01(0.26-7.87)$ & $1.01(0.26-3.88)$ & $2.33(0.26-5.51)$ & 0.619 & 0.229 & 0.031 \\
\hline IL-6 & $8.64(3.14-80.11)$ & $10.38(1.88-116)$ & $36.81(0.86-190)$ & 0.693 & 0.13 & 0.037 \\
\hline IL-10 & $0.7(0.15-3.64)$ & $0.78(0.15-3.4)$ & $1.88(0.15-7.18)$ & 0.738 & 0.049 & 0.024 \\
\hline IL-17A & $9.04(2.26-30.94)$ & $7.57(3.44-15.55)$ & $19.33(4.56-39.44)$ & 0.948 & 0.037 & 0.002 \\
\hline IL-17F & $3.16(0.4-16.21)$ & $3.94(0.4-9.21)$ & $8.38(0.4-23.75)$ & 0.965 & 0.094 & 0.006 \\
\hline IL-21 & $22.43(10.71-75.43)$ & $17.8(0.66-72.2)$ & $36.03(8.3-90.41)$ & 0.301 & 0.818 & 0.191 \\
\hline IL-22 & $22.58(12.85-60.21)$ & $23.04(10.97-36.74)$ & $29.45(9.07-53.01)$ & 0.614 & 0.552 & 0.063 \\
\hline
\end{tabular}




\begin{tabular}{ccccccc} 
IL-23 & $12.16(0.77-103)$ & $12.16(0.77-41.37)$ & $17.29(0.77-77.37)$ & 0.548 & 0.326 & $\mathbf{0 . 0 3 6}$ \\
IL-25 & $0.89(0.29-7.87)$ & $1.05(0.34-2.65)$ & $1.78(0.34-5.24)$ & 0.775 & 0.077 & 0.021 \\
IL-31 & $76.5(36.62-576)$ & $80.45(36.62-216)$ & $147.12(28.54-344)$ & 0.809 & 0.179 & 0.242 \\
IL-33 & $146(20.38-582)$ & $101(41.7-585)$ & $56.92(23.02-463)$ & 1 & 0.161 \\
IFN- $\gamma$ & $3.48(0.71-14.61)$ & $2.9(0.71-29.19)$ & $6.06(0.5-27.97)$ & 0.553 & 0.04 \\
SCD40L & $39.55(16.99-96.48)$ & $38.48(12.21-61.83)$ & $38.27(13.18-111)$ & 0.861 & 0.908 \\
TNF- $\alpha$ & $4.35(1.5-24.95)$ & $4.93(1.42-23.83)$ & $5.79(0.82-16.03)$ & 0.677 & 0.96 \\
\hline
\end{tabular}


Table 5: Correlations between hBD-2, hBD-3, P. gingivalis, gingipain activity, and total protease activity levels. Statistically significant $\mathrm{p}$ values $(p<0.05)$ are indicated with bold.

\section{$\begin{array}{llll}P \text {. gingivalis plaque } & P \text {. gingivalis tissue } & \text { hBD-2 } & \text { hBD-3 }\end{array}$}

Spearman correlation coefficient, $p$-value

\begin{tabular}{|c|c|c|c|c|}
\hline RR plaque & $0.803,<\mathbf{0 . 0 0 1}$ & $0.198,0.177$ & $-0.078,0.600$ & $-0.010,0.949$ \\
\hline RR tissue & $0.195,0.177$ & $0.383, \mathbf{0 . 0 0 7}$ & $0.167,0.256$ & $0.021,0.889$ \\
\hline rR plaque & $0.401, \mathbf{0 . 0 0 5}$ & $0.334, \mathbf{0 . 0 2 0}$ & $-0.009,0.950$ & $0.076,0.609$ \\
\hline rR tissue & $-0.142,0.337$ & $-0.237,0.105$ & $-0.041,0.783$ & $0.101,0.496$ \\
\hline PEK-054 plaque & $-0.136,0.357$ & $-0.336, \mathbf{0 . 0 1 9}$ & $-0.146,0.321$ & $-0.092,0.535$ \\
\hline PEK-054 tissue & $-0.035,0.815$ & $-0.308, \mathbf{0 . 0 3 3}$ & $-0.309, \mathbf{0 . 0 3 3}$ & $-0.417, \mathbf{0 . 0 0 3}$ \\
\hline
\end{tabular}

RR: Gingipain specific substrate that contains D-aminoacids; rR: Gingipain specific substrate that contains L-aminoacids; PEK-054: Substrate to determine total protease enzyme activity 


\section{Figure legends}

Figure 1: Molecular forms and relative levels of hBD-2 (A) and hBD-3 (B) in human gingival samples with different degrees of inflammation. In the western-blot figures, lines $a$ and $b$ are gingival tissue samples, and $\mathrm{c}$ is a synthetic protein.

This article is protected by copyright. All rights reserved 
A)

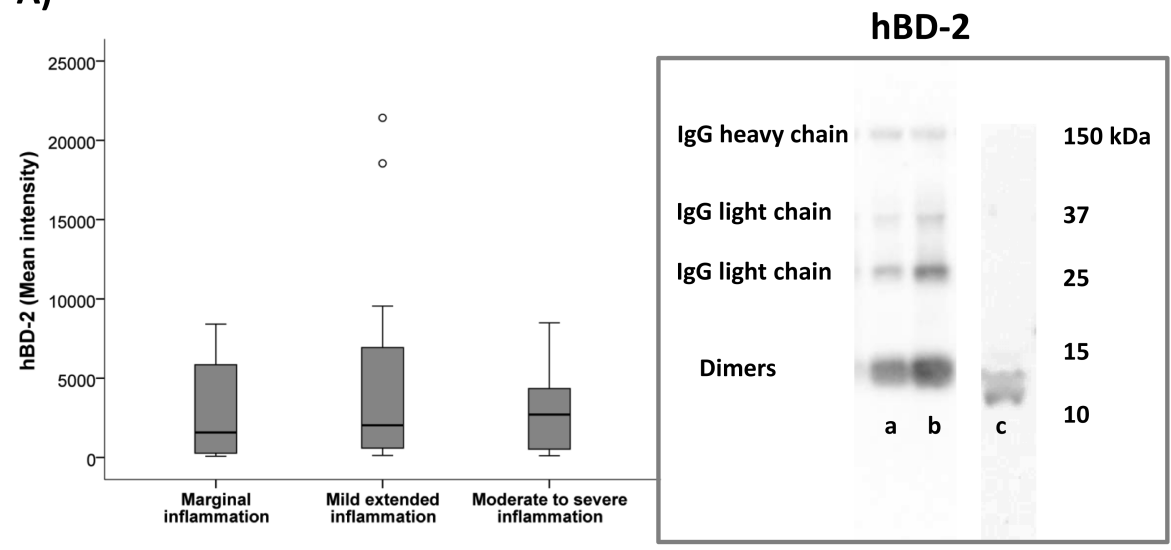

B)

hBD-3

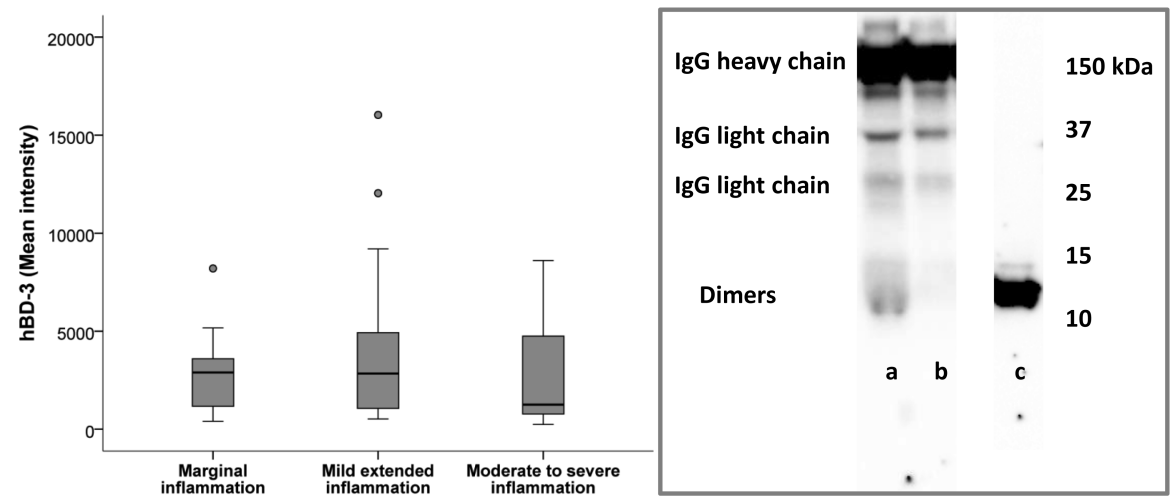

jcpe_13227_f1.tif 